\title{
Modelling Electronic Sharing (E-Sharing) Behaviour: A Perspective on Location-aware Technology
}

\author{
Mutlaq B. Alotaibi \\ Ass ociate Profess or of Information Systems \\ Al Imam Mohammad Ibn Saud Islamic University (IMSIU) \\ Riyadh, Saudi Arabia \\ E-mail: motaibi@imamu.edu.sa
}

\begin{abstract}
The purpose of this paper is to investigate the factors affecting electronic sharing (E-sharing) behaviour, with a particular focus on location-aware technology. Based on an extensive literature review, a structural model consisting of seven factors was proposed to model the E-sharing behaviour of location-based knowledge (LBK). The main constructs were: reward expectancy (WE), reputation expectancy (RE), perceived benefits (PB), perceived trust (PT), attitudes towards LBK, attitudes toward knowledge sharing incentives (KSI) and intention to share knowledge (ISK). The model was examined by empirical data gathered from four hundred and ninety $(n=490)$ respondents. Results herein indicate that attitude toward KSI can be determined by the RE and WE, while attitude toward LBK E-sharing can be predicted by the PB and PT. The two attitude constructs (KSI and LBK) can determine the behavioural ISK. All of the proposed relationships within the model were statistically significant.
\end{abstract}

Index Terms-Location-aware, Knowledge, Trust, Rewards, Reputation, Electronic sharing.

\section{INTRODUCTION}

The rising popularity of location disclosure technology is generating several opportunities for businesses [1]. During recent years, the use of location sharing services (LSS) has been largely adopted in many contexts, particularly by smartphones [1]. Location-based knowledge (LBK) has provided new insights into electronic sharing (E-sharing) behaviour. LBK primarily focuses on linking knowledge with a location at nearly real-time [2]. It evolves at a faster pace than traditional Esharing and has a great influence on consumer decision making. It has been estimated that over half of the human mobility patterns over the globe have been examined through LBK E-sharing software [3]. Little is known about the effect of location disclosure on E-sharing behaviour. Furthermore, several factors rooted in the knowledge sharing (KS) literature are still to be comprehensively investigated in the context of LSS, such as reputation, rewards and incentives.
This paper provides insight into determinants of Esharing behaviour, with a considerable emphasis on attitudes and intentions toward LBK E-sharing. This research considers the way in which consumers share location tagged knowledge, irrespective of any security and privacy concerns. The objectives of this study include (1) modelling the E-sharing behaviour, with a particular focus on LBK E-sharing; (2) explaining the role of trust perceptions in location disclosure behaviour; and (3) evaluating the effect of incentives to motivate knowledge sharing, including reward expectations and reputation inspirations. The inferences from this research are of great relevance to scholars and practitioners.

The current study identified a synergic potential of two separated, but interrelated fields of studies. The scope of this study covers aspects of KS as an application domain of LSS. In fact, several factors were drawn from prior research on $\mathrm{KS}$ and integrated with counterparts from LSS studies. This research was motivated by a considerable lack of focus in the literature on LSS, as well as limited integration of LSS in the KS literature. During the integration endeavour, most of the effort was put on building an integrative model, rather than providing a holistic unified view of the two domains. This offered an initial understanding of LBK E-sharing, but further expansion of the theory is important to maximize the comprehension of the proposed model.

The remainder of this paper is organized as follows. Section 2 provides background information concerned with knowledge E-sharing and technology adoption. The research model and hypotheses are discussed in Section 3. The research method is explained in Section 4, including scale development and survey administration. Data analysis and results are described in Section 5, including the measurement and structural models. A discussion of the results and implications of the study are presented in Section 6 , followed by conclusions and final remarks in Section 7.

\section{THEORETICAL UNDERPINNINGS}

During previous years, knowledge E-sharing has received considerable attention as the main source of 
knowledge about products and services [4]. It was noteworthy that the different between data, information and knowledge is described in [5]. There are several channels for knowledge E-sharing [4], such as virtual communities and social network services (SNS). In particular, it involves different aspects of social support, through which expertise is exchanged among group me mbers in order to guide prospective consumers [4]. For example, travellers share their experiences by rating and writing reviews about hotels in order to guide prospective travellers towards appropriate selections [6]. As KS is linked with human behaviour, people become reluctant to share knowledge when they feel that the possessed knowledge is valuable [7]. Therefore, it is important to tackle knowledge hoarding by motivating knowledge Esharing through emotional and monetary incentives [8]. For example, rewards as a compensation for $\mathrm{KS}$ were found to impact human behaviour in knowledge communities, particularly in supporting individuals' decisions to share [8]. In summary, since E-sharing of knowledge is widely adopted in social and societal contexts, it is usually influenced by human beliefs, thoughts and attitudes.

Recent advances in information technology have altered the ways in which knowledge is exchanged [9]. Using ubiquitous smartphones equipped with a global positioning system (GPS), LSS provides precise information about the location where knowledge is shared [10]. This technological trend has enhanced the interaction between knowledge seekers and contributors, through location tagged knowledge [11]. With a wide variety of applications, LSS provides various opportunities for businesses to promote location-aware initiatives, such as situation awareness [12] and locationbased advertising [13]. In fact, several SNS and standalone mobile applications emerged with LSS, such as Facebook and Foursquare [9, 10]. Despite privacy concerns, people are willing to share their private information, due to the trustworthiness of the LBK Esharing provider [10]. Given the characteristics of LBK E-sharing, it is particularly important to model consumer behaviour in this emerging domain.

In relation to the LBK E-sharing behaviour, this study identified several streams of research within traditional KS behaviour and applications of location-aware technologies. The first stream of research investigated traditional aspects of $\mathrm{KS}$ in two main contexts: organization and individual. First, the scholarly research investigated various aspects of $\mathrm{KS}$ behaviour in an organizational context $[14,15]$. It focused on traditional KS concepts within organizations, such as psychological, organizational, environmental and technological factors. Secondly, some researchers considered aspects of knowledge exchange behaviour by individuals within virtual communities [16, 17]. The scholarly research explored knowledge exchange behaviour among knowledge seekers and contributors in an environment of mutual trust and understanding. This context is similar to the organizational one in investigating traditional KS behaviour, but it focused on contextual and personal aspects of knowledge exchange. This stream of research, with its two contextual areas, lacked focus on the changing human behaviour caused by recent technological advancements. In fact, smartphone and context-aware technologies have altered the way by which knowledge is shared and consumed. In summary, it is rather important to extend human behaviour studies in the context of KS beyond the traditional focus to fit the modern aspects of technological development, such as location awareness.

Another stream of research explored the application of location-aware technologies in two main areas: SNS and mobile advertising ( $\mathrm{M}$-advertising). First, several studies into SNS adoption behaviour focused on privacy concerns resulting from location disclosure and check-in behaviour of SNS users [2, 18, 19]. Researchers in this field investigated several personality factors, disclosure motivations, usage patterns and gender differences. Secondly, another application area of location-aware technologies was M-advertising, in which the focus of scholarly research was similar to that for the SNS area. However, researchers in the M-advertising field incorporated context-specific factors, such as irritation and type of marketing technique [13, 20]. It is noteworthy that these two applications (SNS and M-advertising) are widely adopted and have great potential for further growth. Although the work in this stream of research seems comprehensive, little effort has been made to link KS behaviour with location-aware technologies. Therefore, it can be said that a gap in the literature has been identified, and hence, this study attempts to fill it.

\section{RESEARCH MODEL DEVELOPMENT}

The relationship between perceptual beliefs, attitudes and behavioural intention formed the theoretical foundation for the current KS model [21]. Seven factors were proposed to determine E-sharing behaviour, with a particular focus on LBK E-sharing. In accordance with KS adoption theories [21], the attitude was proposed to mediate the relation between perceptual beliefs and behavioural intention. Due to the scope of the study, the attitudes toward location-based E-sharing was modelled by two constructs, namely attitudes towards knowledge sharing incentives (KSI) and LBK E-sharing. The former denotes the user's beliefs of incentive-based knowledge E-sharing while the latter represents the user's feelings toward LBK E-sharing. In addition, the antecedents of attitudes toward KSI were identified to be reward expectancy (WE) and reputation expectancy (RE). Similarly, the predictors of attitude toward LBK Esharing were determined to be perceived benefit (PB) and perceived trust (PT). All of the proposed relationships within the research model were supported by empirical evidence from prior research. Fig. 1 shows the research model and the subsequent section will present theoretical justifications for the association between the variables.

Knowledge E-sharing involves several sacrifices, such as loss of power, time and effort, that hinder knowledge E-sharing intentions [22]. Therefore, many organizations 
have offered E-sharing incentives in order to compensate individuals who are active in knowledge exchange and dissemination [23]. For example, a vendor can reward knowledge E-sharing activities with financial payments or loyalty rewards [23]. Despite the effect of economic rewards, some self-motivated individuals seek recognition and respect in their social structure more than financial benefits [24]. Therefore, they are willing to exchange valuable knowledge for social returns, such as reputation, gratitude and a knowledgeability status [24]. Prior research indicated that reward expectancy and reputation expectancy have important roles to play in improving attitudes toward knowledge E-sharing. For example, Chennamaneni, Teng, and Raja (2012) provided salient evidence supporting the fact that both reward and reputation expectancy are determinants of attitudes toward knowledge E-sharing. It is noteworthy that recent studies in KS literature revealed a strong correlation between the two motivational factors of reward and reputation [24]. This could be attributed to several expected gains, particularly economic and financial benefits, resulting from an improved image and increased social status. Therefore, the association between the two factors (RE and WE) can be hypothesized. In summary, it can be theorized that RE and WE are antecedents of the attitudes towards knowledge E-sharing incentives. In addition, RE has a great positive influence on WE. To illustrate:

H1: Reward expectancy is positively associated with incentive-based attitudes toward knowledge E-sharing.

H2: Reputation expectancy is positively associated with incentive-based attitudes toward knowledge Esharing.

H3: Reputation expectancy is positively associated with reward expectancy.

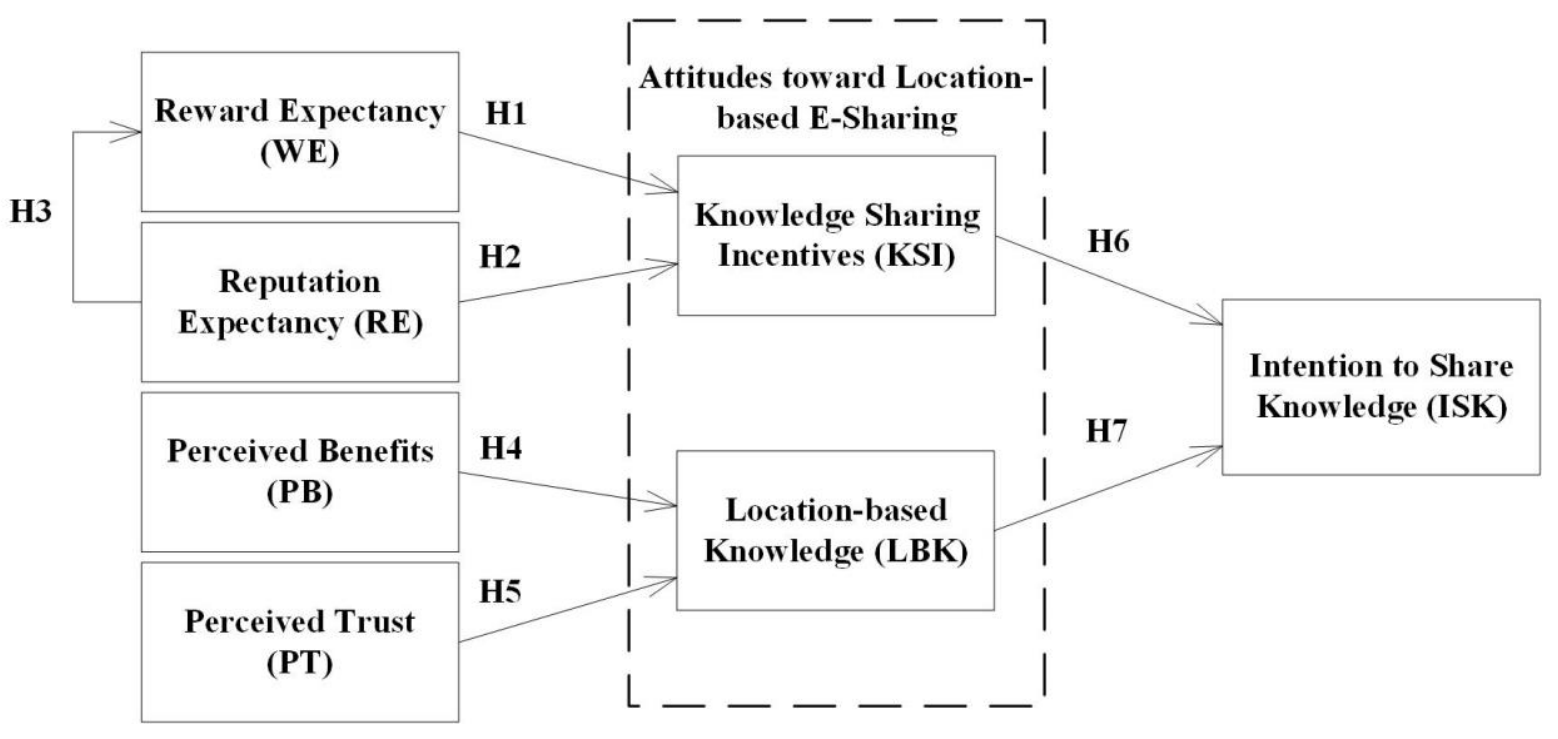

Fig.1. Research Model.

Sharing user locations through a GPS provides salient benefits for mobile businesses, particularly for mobile commerce and location-based advertising [25]. However, this might raise several privacy concerns, because location information can be used to determine the user's identity and movement patterns without the user's consent [26]. Therefore, trust is seen as an important factor in LBK E-sharing, particularly trust in the provider's ability to protect private data from being invaded [26]. Related studies from the location-based Esharing literature suggest that the PB and PT have a great influence on attitudes towards LBK E-sharing. In general, the PT has been shown to be among the key predictors of attitudes towards KS [27]. In addition, a study by Peralta and Saldanha (2014) on the role of PT on KS behaviour suggested that trust propensity fosters KS behaviour. Another study by Beldad and Kusumadewi (2015), on the effect of PT and PB on location-sharing mobile services in Indonesia, found both the PT and PB to be positively associated with attitudes towards LBK E-sharing. The study also revealed that competence-based trust and general trust of the LBK community are among the determinants of LBK E-sharing behaviour [9]. A study by Koohikamali, Gerhart, and Mousavizadeh (2015) on LBK E-sharing provided salient evidence that the $\mathrm{PB}$ is a strong predictor of attitudes towards LBK E-sharing. Similarly, a study by Sun, Wang, Shen and Zhang (2015) found that a strong relationship between the PB and attitudes towards LBK E-sharing exist in the context of social network services. Therefore, it can be hypothesized that attitudes towards LBK E-sharing can be predicted by the PB and PT. To illustrate:

H4: Perceived benefit is positively associated with attitudes toward location-based knowledge.

H5: Perceived trust is positively associated with attitudes toward location-based knowledge.

In human behaviour literature, attitudes represent an expression (belief, feeling) of favour or disfavour towards a certain behaviour [28]. According to the technology adoption theories, attitude is modelled as a key antecedent of behavioural intention [29]. In the context of knowledge sharing, a relationship between attitude and 
intention was found to exist [27]. In particular, attitudes toward KS were found to be the strongest predictor of behavioural intention to share knowledge [14]. As opposed to knowledge sharing, some cultural norms promote knowledge hoarding, whereby experts hide important knowledge irrespective of any negative consequences [30]. It is, therefore, important to motivate employees to share knowledge by implementing incentive systems to promote teamwork and reward cooperation [30]. In the context of LBK, a study by Koohikamali, Gerhart, and Mousavizadeh (2015), on LBK E-sharing through social network services, revealed that attitudes towards LBK E-sharing and attitudes towards KSI are both key predictors of intention to share LBK. Another study by Limpf and Voorveld (2015), on users' attitudes towards LBK E-sharing in the context of $\mathrm{M}$-advertising, provided empirical evidence supporting a strong association between attitudes toward LBK Esharing and intention to share knowledge. Therefore, it can be hypothesized that intention to share knowledge can be determined by attitudes toward KSI and attitudes towards LBK E-sharing. To illustrate:

H6: Attitude toward knowledge sharing incentives is positively associated with intention to share knowledge.

H7: Attitude toward LBK E-sharing is positively associated with intention to share knowledge.

\section{RESEARCH METHOD}

This study was designed as quantitative research that inherently emphasizes the measurement process [31]. The observations of this empirical investigation were measured by means of an online questionnaire. The following section describes the scale development and survey adminis tration.

\section{A. Scale Development}

In order to test the research hypotheses, a research instrument (questionnaire) was devised. The instrument consisted of three main sections: demographics, Esharing factors and comments. The first section (demographics) aimed to collect demographic information related to the gender, age and education of the sample. The second section covered the E-sharing behaviour influential factors, including dependent and independent variables. In fact, the scale items for each variable were developed in accordance with prior related research. For example, the scale items for WE were adapted from Hau et al. and Chang et al. [23, 24], while the RE was measured by items modified from Chang et al. [24]. Furthermore, the items utilized to measure the ISK were adapted from Chang et al. and Lin [24, 32]. The scale items for the attitudes toward KSI were adapted from Kaul [33]. In addition, in order to develop a scale for PT, items were adopted from Beldad and Kusumadewi [9] with minor modifications to fit the context of LBK E-sharing. The scale items for measuring the PB and attitude toward LBK E-sharing were modified from Koohikamali Gerhart, and Mousavizadeh [18]. The items were measured by a seven-point Likert-type scale [34], with anchors ranging from 7 (strongly agree) to 1 (strongly disagree). Finally, the last section allowed the respondents to comment on the study and provide recommendations and notes. The research instrument, including the variables and indicators, is shown in Appendix A. In summary, the variables have been measured by several items taken from related research, but tailored to fit the context at hand.

\section{B. Survey Administration}

Prior to the distribution phase, the content of the instrument was examined for validity by a panel of experts. The experts highlighted several parts of the instrument that needed further rev ision and improvement, such as questionnaire format and sentence structure. The advice offered by the experts was taken into consideration in the final instrument version, which was then transferred into an online questionnaire. During the distribution phase, a short message was attached to the questionnaire explaining the purpose of the study and encouraging respondents to participate. It is noteworthy that the main channels for questionnaire distribution were social media, personal electronic mails and knowledge community forums in Saudi Arabia. After two months of a field survey, the study yielded five hundred and seventy-eight $(n=578)$ responses. Over $15 \%$ of the responses were eliminated, due to duplication, invalidity and inconsistency, resulting in four hundred and ninety $(n=490)$ usable responses. In summary, the instrument validity and improvement phase preceded a field survey that yielded a relatively adequate sample size.

Table 1. Sample Characteristics

\begin{tabular}{|c|c|c|c|}
\hline \multicolumn{2}{|c|}{ Respondent Demographics } & Frequency & Percent \\
\hline & Total & 490 & 100 \\
\hline \multirow[t]{2}{*}{ Gender } & Male & 260 & 53.1 \\
\hline & Female & 230 & 46.9 \\
\hline \multirow[t]{6}{*}{ Age } & Less than 17 & 12 & 2.4 \\
\hline & $18-24$ & 116 & 23.7 \\
\hline & $25-34$ & 252 & 51.4 \\
\hline & $35-44$ & 92 & 18.8 \\
\hline & $45-54$ & 12 & 2.4 \\
\hline & 55 and above & 6 & 1.2 \\
\hline \multirow[t]{5}{*}{ Education } & High school or under & 40 & 8.2 \\
\hline & Two years diploma & 40 & 8.2 \\
\hline & Bachelor & 302 & 61.6 \\
\hline & Master & 84 & 17.1 \\
\hline & Ph.D. & 24 & 4.9 \\
\hline
\end{tabular}

Table 1 demonstrates the sample characteristics. At a glance, most of the respondents were university graduates and postgraduates aged between 18 and 44. Despite a small difference between the number of male and female respondents, it can be said that the two gender categories were adequately represented. In detail, it can be seen from the table that the number of male respondents was greater than female, with $53.1 \%$ being men and $46.9 \%$ being women. With regard to age, the table showed that 
over half of the sample were aged between 25 and 34 . The age range from 18 to 24 came next with $23.7 \%$ of the sample. In addition, more than $18 \%$ of the sample were aged between 35 and 44, while limited responses were recorded from other age ranges (less than 17, 45-54 and over 55), with figures failing to exceed $2.5 \%$ of the sample size. With regard to education, the responses came largely from university graduates, as over $60 \%$ of the respondents had a bachelor's degree. Postgraduates were also showed be involved during the course of data gathering, as over $17 \%$ of the respondents had a master's degree and almost $5 \%$ of the sample were $\mathrm{Ph} . \mathrm{D}$. holders. The lower educated individuals were also represented, with $8.2 \%$ of individuals having an educational level no higher than high school and $8.2 \%$ of counterparts having a two-year diploma.

\section{DATA ANALYSIS AND RESULTS}

\section{A. Measurement Model}

Table 2 shows the factor loadings and indicators of the constructs reliability and internal consistency. Overall, the measurement scale was demonstrated to be adequate with regard to reliability and internal consistency measures. In fact, the estimates for factor loadings exceeded the accepted level of 0.7 [35], with measures ranging from 0.711 to 0.935 . In addition, the measures for composite reliability (CR) were greater than the benchmark of 0.7 [36, 37], with values ranging from 0.885 to 0.94 . Similarly, the estimates for the average variance extracted (A VE) were greater than the threshold of $0.5[35,38]$, with estimates ranging from 0.719 to 0.8 . The scale also demonstrated a remarkable internal consistency (IC), with measures for Cronbach alpha $(\alpha)$ being over the recommended value of 0.7 [35], particularly between 0.881 and 0.939 . Furthermore, the constructs were examined by estimates for convergent and discriminant validity. Table 3 shows the correlation matrix of the constructs, in which evidence of convergent and discriminant validity is provided, as correlation coefficients between the construct and itself were demonstrated to be greater than those for other constructs [39]. In summary, the estimates for the scale validity, reliability and internal consistency supported the adequacy of the measurement scale.

Table 2. Factor Loadings and Indicators of Internal Consistency and Reliability

\begin{tabular}{|c|c|c|c|c|c|c|}
\hline Construct & Item & Factor loading & $\mathrm{t}$-value & $\mathrm{CR}$ & AVE & IC \\
\hline \multirow[t]{4}{*}{ WE } & WE1 & 0.944 & 11.158 & \multirow[t]{4}{*}{0.940} & \multirow[t]{4}{*}{0.798} & \multirow[t]{4}{*}{0.939} \\
\hline & WE2 & 0.94 & 11.379 & & & \\
\hline & WE3 & 0.92 & 12.582 & & & \\
\hline & WE4 & 0.756 & 14.917 & & & \\
\hline \multirow[t]{4}{*}{$\mathrm{RE}$} & RE1 & 0.821 & 14.716 & \multirow[t]{4}{*}{0.941} & \multirow[t]{4}{*}{0.800} & \multirow[t]{4}{*}{0.939} \\
\hline & RE2 & 0.931 & 12.805 & & & \\
\hline & RE3 & 0.933 & 12.677 & & & \\
\hline & RE4 & 0.888 & 14.044 & & & \\
\hline \multirow[t]{3}{*}{ ISK } & ISK1 & 0.922 & 10.426 & \multirow[t]{3}{*}{0.908} & \multirow[t]{3}{*}{0.768} & \multirow[t]{3}{*}{0.910} \\
\hline & ISK2 & 0.837 & 13.486 & & & \\
\hline & ISK3 & 0.868 & 12.899 & & & \\
\hline \multirow[t]{3}{*}{ KSI } & KSI1 & 0.841 & 14.273 & \multirow[t]{3}{*}{0.902} & \multirow[t]{3}{*}{0.755} & \multirow[t]{3}{*}{0.871} \\
\hline & KSI2 & 0.93 & 12.321 & & & \\
\hline & KSI3 & 0.832 & 14.987 & & & \\
\hline \multirow[t]{3}{*}{ PT } & PT 1 & 0.911 & 10.479 & \multirow[t]{3}{*}{0.915} & \multirow[t]{3}{*}{0.782} & \multirow[t]{3}{*}{0.914} \\
\hline & PT2 & 0.817 & 13.824 & & & \\
\hline & PT3 & 0.922 & 11.094 & & & \\
\hline \multirow[t]{4}{*}{ PB } & $\begin{array}{l}\text { PB1 } \\
\end{array}$ & 0.857 & 13.063 & \multirow[t]{4}{*}{0.915} & \multirow[t]{4}{*}{0.732} & \multirow[t]{4}{*}{0.917} \\
\hline & PB2 & 0.711 & 14.71 & & & \\
\hline & PB3 & 0.902 & 11.325 & & & \\
\hline & PB4 & 0.935 & 11.042 & & & \\
\hline \multirow[t]{3}{*}{ LBK } & LBK1 & 0.781 & 13.011 & \multirow[t]{3}{*}{0.885} & \multirow[t]{3}{*}{0.719} & \multirow[t]{3}{*}{0.881} \\
\hline & LBK2 & 0.86 & 10.471 & & & \\
\hline & LBK3 & 0.899 & 11.656 & & & \\
\hline
\end{tabular}


Table 3. Correlation Matrix

\begin{tabular}{|c|c|c|c|c|c|c|c|}
\hline Latent Variable & WE & ISK & LBK & KSI & PB & RE & PT \\
\hline WE & 0.893 & & & & & & \\
\hline ISK & 0.872 & 0.876 & & & & & \\
\hline LBK & 0.641 & 0.761 & 0.848 & & & & \\
\hline KSI & 0.828 & 0.787 & 0.626 & 0.869 & & & \\
\hline PB & 0.814 & 0.771 & 0.601 & 0.800 & 0.856 & & \\
\hline RE & 0.833 & 0.834 & 0.675 & 0.840 & 0.817 & 0.894 & \\
\hline PT & 0.876 & 0.794 & 0.655 & 0.866 & 0.776 & 0.822 & 0.885 \\
\hline
\end{tabular}

\section{B. Structural Model}

Table 4 shows the model fit indices. Overall, all the quality-of-fit measures supported the model fit. In particular, it can be seen from the table that the ratio of $(\chi 2 / \mathrm{df})$ was lower than the benchmark of 5.00 [40]. Moreover, the estimate for RMSEA was adequate, with a value of 0.078 that was lower than the threshold of 0.08 [41]. The SRMR measure was relatively small, as recommended [42]. The measures for IFI, CFI, TLI and NFI were all greater than the benchmark of 0.90 [43]. In summary, the model was demonstrated to be a good fit with regard to the seven model fit indices.

Table 4. Model Fit Indices

\begin{tabular}{|l|c|c|}
\hline Quality-of-Fit Measure & Structural Model & Acceptable Value \\
\hline Chi-square/degree of freedom $\left(\chi^{2 / d f)}\right.$ & 4.728 & $<5.00$ \\
\hline Root Mean Square Error Approximation (RMSEA) & 0.078 & $\leqslant 0.08$ \\
\hline Standardized RMR (SRMR) & 0.0368 & the smaller the better \\
\hline Incremental Fit Index (IFI) & 0.928 & $\geqslant 0.90$ \\
\hline Comparative Fit Index (CFI) & 0.927 & $\geqslant 0.90$ \\
\hline Tucker Lewis Index (TLI) & 0.917 & $\geqslant 0.90$ \\
\hline Normed Fit Index (NFI) & 0.911 & $\geqslant 0.90$ \\
\hline
\end{tabular}

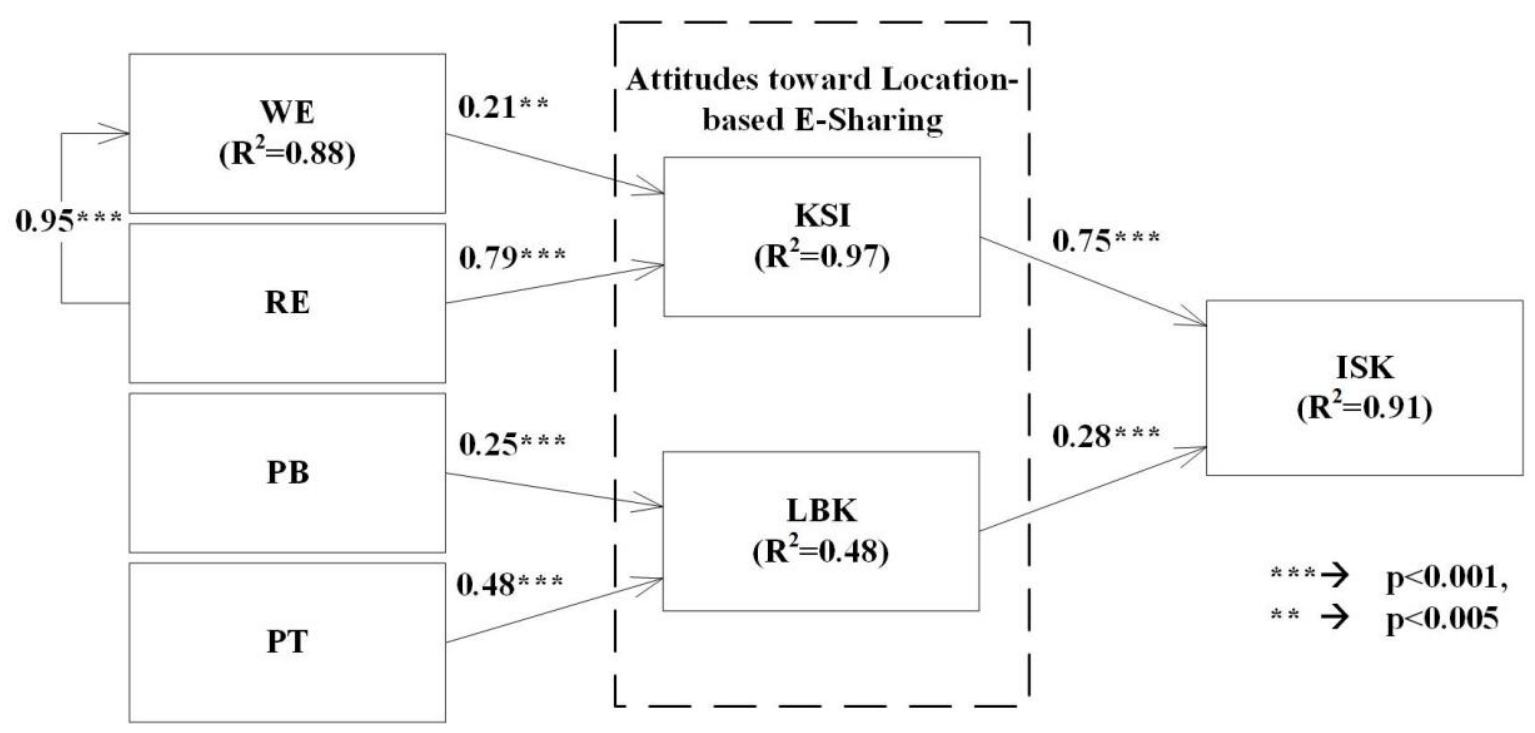

Fig.2. Results of the Structural Model.

Fig. 2 shows the results of the structural model. Basically, the $\mathrm{R}^{2}$ measures were utilized to examine whether the model fit the empirical data and results revealed a considerable goodness-of-fit. In fact, the structural model explains $91 \%$ variance of ISK, $97 \%$ variance of the attitudes toward KSI and $48 \%$ variance of the attitudes toward LBK. The path analysis was utilized to describe the correlation between the model factors using path coefficient estimates (standardized $\beta$ ). At a glance, results revealed that all relationships proposed in the structural model were supported by the empirical data. It can be seen from the figure that all variables were positively related in accordance with the proposition, and path estimates were statistically significant. In particular, the attitudes toward KSI can be determined by WE and RE. The RE was found to be the most important factor to predict attitudes toward KSI (with a path coefficient of standardized $\beta=0.79$ ). The correlation between RE and WE was found to be strong (with a path coefficient of standardized $\beta=0.95)$. The WE can also determine the 
attitude toward KSI (with a path coefficient of standardized $\beta=0.21$ ). With regard to antecedents of attitudes toward LBK, PT was demonstrated to be the strongest predictor of attitudes toward LBK (with a path coefficient of standardized $\beta=0.48$ ), followed by the PB (with a path coefficient of standardized $\beta=0.25$ ). In addition, results indicated that ISK can be determined by both attitude factors (KSI and LBK). In particular, the attitude toward KSI was demonstrated to be the strongest predictor of ISK (with a path coefficient of standardized $\beta=0.75$ ), followed by the attitude toward LBK (with a path coefficient of standardized $\beta=0.28$ ). In summary, the path analysis results revealed that attitudes towards KSI and LBK can predict the KSI. Moreover, the WE and RE were key antecedents of the attitude toward KSI, while the PB and PT were linked to the attitude toward LBK.

\section{DISCUSSION AND IMPLICATIONS}

Table 5 summarizes the hypotheses testing results. Overall, it can be seen from the table that all hypotheses were supported by empirical data. In particular, the RE was proved to be a salient pred ictor of the attitude toward KSI, presenting more explanatory power than the WE, thus supporting the first and second hypotheses $(H I$ and H2). The third hypothesis (H3) was also supported, confirming the strong correlation between the WE and RE. Furthermore, the fourth and fifth hypotheses ( $H 4$ and H5) were supported, as the PT and PB exhibited direct and significant effects on the attitude toward LBK. Finally, the attitude toward KSI presented as the key determinant of ISK, showing stronger prediction ability than the attitude toward LBK, thus supporting the sixth and seventh hypotheses (H6 and H7). In brief, the empirical results supported all of the research hypotheses, with statistical significance.

The main implications of this research involve segmentation aspects of KS motivations and the associated marketing techniques. The findings indicate that LBK contributors seek either emotional value (reputation and recognition) or monetary returns (economic value and reward). Such segmentation of LBK contributors is consistent with prior research [14, 23, 44]. In this respect, marketing managers can motivate LBK contributors with various techniques tailored for each customer segment. If recognition is sought, the managers can improve the image of frequent contributors through inclusion in a top contributor list, after being rated by knowledge seekers. If monetary value is sought, LBK Esharing can be encouraged by means of reward schemes, whereby contributors earn points for each LBK E-sharing activity and hence are entitled to various options for reward redemption. The experience gained from this empirical research emphasized RE as the main predictor of $\mathrm{KS}$ activities in the context of LBK E-sharing. This finding is also consistent with related studies [14, 24]. Furthermore, even WE can be predicted by RE, as the relationship between them has been shown to have the strongest exploratory power $(\beta=95 \%)$. This finding is supported by regular observations that famous people can gain valuable financial benefits by utilizing their reputation, for example, famous users advertising on social media. In summary, categorizing LBK E-sharing motivations can facilitate effective marketing strategies for LBK E-sharing services.

Table 5. Summary of Hypothesis Testing Results

\begin{tabular}{|c|c|c|c|c|c|}
\hline Hypothesis & Path & Path coefficient $(\beta)$ & t-value & Supported? & Notes \\
\hline$H 1$ & WE $\rightarrow$ KSI & $0.21 * *$ & 2.93 & Yes & Direct effects \\
\hline$H 2$ & RE $\rightarrow$ KSI & $0.79 * * *$ & 10.35 & Yes & Direct effects \\
\hline$H 3$ & RE $\rightarrow$ WE & $0.95 * * *$ & 29.29 & Yes & Direct effects \\
\hline$H 4$ & PB $\rightarrow$ LBK & $0.25 * * *$ & 3.73 & Yes & Direct effects \\
\hline$H 5$ & PT $\rightarrow$ LBK & $0.48^{* * *}$ & 7.14 & Yes & Direct effects \\
\hline$H 6$ & KSI $\rightarrow$ ISK & $0.75 * * *$ & 19.19 & Yes & Direct effects \\
\hline$H 7$ & LBK $\rightarrow$ ISK & $0.28 * * *$ & 8.96 & Yes & Direct effects \\
\hline
\end{tabular}

The findings of this research provide implications for E-sharing service providers, with a particular focus on the role of user trust and perceived benefits of LBK. Despite several privacy concerns, it can be concluded that users are willing to share LBK, because of their trust in LBK E-sharing providers. Therefore, E-sharing service providers should promote social interaction and build an environment of mutual understanding and trust among LBK contributors and seekers. This finding is consistent with related research [9, 22, 27]. Another academic implication of this research stresses the importance of attitudes toward location-based E-sharing. Academics may notice that attitude to toward location-based Esharing was divided into two types: attitudes toward KSI and LBK. It is noteworthy that antecedents of the former were not correlated with the latter and vice-versa. The separation of attitude types facilitates an in-depth understanding of the relationship between the attitude factor and its determinants. In summary, several implications of this research have been discussed to serve academics and practitioners alike.

Despite the valuable insights provided by this research, several limitations were encountered, and also can offer several opportunities for further research. In fact, since a survey method was adopted, the outcome of this research could be biased, due to several inherited limitations. One of the variance sources might be the selection of the sample (sample selection variance). Another possible 
variance cause is the common method variance [45]. Another limitation was related the effect of culture on the generalizability of the findings, as this research was conducted only in Saudi Arabia. In addition, this study focused on the attitude factors and antecedents, however, modelling of LBK E-sharing requires the incorporation of several influential factors. Therefore, it can be concluded that this model represented an initial study that opens new directions for further research. This could be achieved by extending the model and incorporating additional factors, such as perceived behavioural control and subjective norms [14]. In addition, potential factors could be drawn from the KS literature, such as altruis $m$ and expected relationships [44]. In summary, although limitations of this study involve several variance sources, it stressed the importance of extending the proposed model.

\section{CONCLUSION}

This paper reported an empirical investigation into LBK E-sharing attitudes and intentions. A research model was proposed in accordance with relevant literature to predict the E-sharing behaviour of LBK. The model consisted of seven main constructs and seven main hypotheses that explain the relationship between the construct. The constructs were WE, RE, PB, PT, attitude toward KSI, attitude toward LBK and ISK. Survey data was collected from four hundred and ninety $(n=490)$ participants to empirically examine the model. Results indicate an appropriate fit of the research model, as all of the hypotheses were accepted. The attitude constructs (KSI and LBK) were demonstrated to be key antecedents of the KSI. The attitude toward KSI can be determined by the WE and RE, whereas the attitude toward LBK can be predicted by PB and PT. Implications and limitations of this research have been discussed. Recommendations for further research were provided.

\section{APPENDIX A VARIABLES AND INDICATORS}

\section{WE [23, 24]}

WE1. It is important to be rewarded when I share my knowledge.

WE2. It is important to receive monetary rewards in return for my knowledge sharing.

WE3. It is important to receive loyalty points in return for my knowledge sharing.

WE4. Overall, I expect to be compensated for knowledge sharing.

\section{RE [24]}

RE1. Sharing my knowledge improves my image within the community.

RE2. Individuals who share their knowledge have more prestige than those who do not.

RE3. Sharing my knowledge improves others' recognition of me.

RE4. When I share my knowledge, I gain the respect of the people around me.
ISK $[24,32]$

ISK1. I will share my knowledge on a regular basis in the future.

ISK2. I intend to share knowledge with my colleagues more frequently in the future.

ISK3. I will strongly recommend others to share knowledge.

\section{Attitudes toward KSI [33]}

KSI1. It is a good idea to compensate knowledge sharing activities with incentives.

KSI2. I have a positive attitude toward knowledge sharing incentives.

KSI3. I like to get some benefits in return for my knowledge sharing.

\section{PT [9]}

PT1. The LBK provider I'm using is competent in protecting my location information.

PT2. The LBK provider I'm using has the knowledge of how to protect users' location information.

PT3. The LBK provider I'm using uses the right technology to protect my information from third-party access.

\section{PB [18]}

PB1. I benefit from others when I use shared LBK.

PB2. Using LBK E-sharing has many advantages for society.

PB3. When I share LBK, I benefit others.

PB4. In general, when people use LBK E-sharing, they help others around them.

\section{Attitudes toward LBK E-sharing [18]}

LBK1. It is a good idea to use LBK E-sharing.

LBK2. I have a positive attitude toward using LBK Esharing.

LBK3. I like using LBK E-sharing.

\section{REFERENCES}

[1] S. Patil, G. Norcie, A. Kapadia, and A. Lee, "Check out where i am!: location-sharing motivations, preferences, and practices," in CHI'12 Extended Abstracts on Human Factors in Computing Systems, 2012, pp. 1997-2002: ACM.

[2] M. J. Chorley, R. M. Whitaker, and S. M. Allen, "Personality and location-based social networks," Computers in Human Behavior, vol. 46, pp. 45-56, 2015.

[3] Z. Cheng, J. Caverlee, K. Lee, and D. Z. Sui, "Exploring Millions of Footprints in Location Sharing Services," ICWSM, vol. 2011, pp. 81-88, 2011.

[4] C. W. Yoo, Y. J. Kim, and G. L. Sanders, "The impact of interactivity of electronic word of mouth systems and EQuality on decision support in the context of the emarketplace," Information \& Management, vol. 52, no. 4, pp. 496-505, 2015.

[5] M. Malhotra and T. G. Nair, "Evolution of Knowledge Representation and Retrieval Techniques," International Journal of Intelligent Systems and Applications, vol. 7, no. 7, p. 18, 2015.

[6] A. Bilgihan, A. Barreda, F. Okumus, and K. Nusair, "Consumer perception of knowledge-sharing in travel- 
related Online Social Networks," Tourism Management, vol. 52, pp. 287-296, 2016.

[7] C.-Y. L. Logistics, "The study of the antecedents of knowledge sharing behavior," Internet Research: Electronic Networking Applications and Policy, vol. 26, no. 4, pp. 845-868, 2016.

[8] A. von der Trenck, F. Emamjome, T. Neben, and A. Heinzl, "What's in it for Me? Conceptualizing the Perceived Value of Knowledge Sharing," in System Sciences (HICSS), 2015 48th Hawaii International Conference on, 2015, pp. 3920-3928: IEEE.

[9] A. Beldad and M. C. Kusumadewi, "Here's my location, for your information: The impact of trust, benefits, and social influence on location sharing application use among Indonesian university students," Computers in human behavior, vol. 49, pp. 102-110, 2015.

[10] H.-S. Kim, "What drives you to check in on Facebook? Motivations, privacy concerns, and mobile phone involvement for location-based information sharing," Computers in Human Behavior, vol. 54, pp. 397-406, 2016.

[11] R. Beck, I. Pahlke, and C. Seebach, "Knowledge Exchange and Symbolic Action in Social Media-Enabled Electronic Networks of Practice: A Multilevel Perspective on Knowledge Seekers and Contributors," MIS quarterly, vol. 38, no. 4, pp. 1245-1270, 2014.

[12] S. K. Das and D. Pal, "Formulation of FISPLAN: A Fuzzy Logic based Reactive Planner for AUVs towards Situation Aware Control," International Journal of Intelligent Systems and Applications, vol. 5, no. 9, p. 47, 2013.

[13] N. Limpf and H. A. Voorveld, "Mobile Location-Based Advertising: How Information Privacy Concerns Influence Consumers' Attitude and Acceptance," Journal of Interactive Advertising, vol. 15, no. 2, pp. 111-123, 2015.

[14] A. Chennamaneni, J. T. Teng, and M. Raja, "A unified model of knowledge sharing behaviours: theoretical development and empirical test," Behaviour \& Information Technology, vol. 31, no. 11, pp. 1097-1115, 2012.

[15] R. Fullwood, J. Rowley, and R. Delbridge, "Knowledge sharing amon gst academics in UK universities," Journal of Knowledge Management, vol. 17, no. 1, pp. 123-136, 2013.

[16] C.-J. Chen and S.-W. Hung, "To give or to receive? Factors influencing members' knowledge sharing and community promotion in professional virtual communities," Information \& Management, vol. 47, no. 4, pp. 226-236, 2010.

[17] C.-M. Chiu, M.-H. Hsu, and E. T. Wang, "Understanding knowledge sharing in virtual communities: An integration of social capital and social cognitive theories," Decision support systems, vol. 42, no. 3, pp. 1872-1888, 2006.

[18] M. Koohikamali, N. Gerhart, and M. Mousavizadeh, "Location disclosure on LB-SNAs: The role of incentives on sharing behavior," Decision Support Systems, vol. 71, pp. 78-87, 2015.

[19] Y. Sun, N. Wang, X.-L. Shen, and J. X. Zhang, "Location information disclosure in location-based social network services: Privacy calculus, benefit structure, and gender differences," Computers in Human Behavior, vol. 52, pp. 278-292, 2015.

[20] M. M. Tsang, S.-C. Ho, and T.-P. Liang, "Consumer attitudes toward mobile advertising: An empirical study," International journal of electronic commerce, vol. 8, no. 3, pp. 65-78, 2004.

[21] H.-L. Yang and C.-Y. Lai, "Understanding knowledgesharing behaviour in Wikipedia," Behaviour \& Information Technology, vol. 30, no. 1, pp.131-142, 2011.

[22] C. F. Peralta and M. F. Saldanha, "Knowledge-centered culture and knowledge sharing: the moderator role of trust propensity," Journal of Knowledge Management, vol. 18, no. 3, pp. 538-550, 2014.

[23] Y. S. Hau, B. Kim, H. Lee, and Y.-G. Kim, "The effects of individual motivations and social capital on employees' tacit and explicit knowledge sharing intentions," International Journal of Information Management, vol. 33, no. 2, pp. 356-366, 2013.

[24] Y.-W. Chang, P.-Y. Hsu, W.-L. Shiau, and C.-C. Tsai, "Knowledge sharing intention in the United States and China: a cross-cultural study," European Journal of Information Systems, vol. 24, no. 3, pp. 262-277, 2015.

[25] S. Lee, K. J. Kim, and S. S. Sundar, "Customization in location-based advertising: Effects of tailoring source, locational congruity, and product involvement on ad attitudes," Computers in Human Behavior, vol. 51, pp. 336-343, 2015.

[26] E. S.-T. Wang and R.-L. Lin, "Perceived quality factors of location-based apps on trust, perceived privacy risk, and continuous usage intention," Behaviour \& Information Technology, pp. 1-9, 2016.

[27] F. Hassandoust, R. Logeswaran, and M. Farzaneh Kazerouni, "Behavioral factors influencing virtual knowledge sharing: theory of reasoned action," Journal of Applied Research in Higher Education, vol. 3, no. 2, pp. 116-134, 2011.

[28] W. E. Nwagwu and B. Famiyesin, "Acceptance of mobile advertising by consumers in public service institutions in Lagos, Nigeria," The Electronic Library, vol. 34, no. 2, pp. 265-288, 2016.

[29] F.-Y. Kuo and M.-L. Young, "Predicting knowledge sharing practices through intention: A test of competing models," Computers in Human Behavior, vol. 24, no. 6, pp. 2697-2722, 2008.

[30] H. Boateng and F. G. Agyemang, "A qualitative insight into key determinants of knowledge sharing in a public sector institution in Ghana," Information Development, vol. 32, no. 1, pp. 35-43, 2016.

[31] L. M. Given, The Sage encyclopedia of qualitative research methods. Sage Publications, 2008.

[32] H.-F. Lin, "Effects of extrinsic and intrinsic motivation on employee knowledge sharing intentions," Journal of information science, 2007.

[33] S. Kaul, "Incentives and Reputation as Predictors for Privacy Concerns and People's Willingness to disclose Information to E-Vendors," Master, Factulty Behavioural, Management and Social Sciences (BMS), University of Twente, Netherlands, 2016.

[34] G. Norman, "Likert scales, levels of measurement and the "laws" of statistics," Advances in health sciences education, vol. 15, no. 5, pp. 625-632, 2010.

[35] W. W. Chin, "The partial least squares approach to structural equation modeling," Modern methods for business research, vol. 295, no. 2, pp. 295-336, 1998.

[36] C. E. Werts, R. L. Linn, and K. G. Jöreskog, "Intraclass reliability estimates: Testing structural assumptions," Educational and Psychological measurement, vol. 34, no. 1, pp. 25-33, 1974.

[37] J. F. Hair, W. C. Black, B. J. B abin, R. E. Anderson, and R. L. Tatham, Multivariate data analysis. Upper Saddle River, NJ, USA: Pearson Prentice Hall, 2006.

[38] C. Fornell and D. F. Larcker, "Evaluating structural equation models with unobservable variables and measurement error," Journal of marketing research, pp. 39-50, 1981.

[39] R. E. Lucas, E. Diener, and E. Suh, "Discriminant validity of well-being measures," Journal of personality and social psychology, vol. 71, no. 3, pp. 616-628, 1996. 
[40] R. P. Bagozzi and Y. Yi, "On the evaluation of structural equation models," Journal of the academy of marketing science, vol. 16, no. 1, pp. 74-94, 1988.

[41] M. W. Browne and R. Cudeck, "Alternative Ways of Assessing Model Fit in Testing Structural Equation Models," in Testing Structural Equation Models, K. B. a. J. Long, Ed.: SAGE publications, 1993, pp. 136-162

[42] B. M. Byrne, Structural Equation Modeling with Lisrel, Prelis, and Simplis: Basic Concepts, Applications, and Programming. Taylor \& Francis Group, 2014.

[43] L.-T. Hu and P. M. Bentler, "Evaluating model fit," in Structural equation modelling: Concepts, issues, and applications, R. H. Hoyle, Ed. Thousand Oaks, CA: SAGE publications, 1995, pp. 76-99.

[44] C.-L. Hsu and J. C.-C. Lin, "Acceptance of blog usage: The roles of technology acceptance, social influence and knowledge sharing motivation," Information \& management, vol. 45, no. 1, pp.65-74, 2008.

[45] S.-J. Chang, A. Van Witteloostuijn, and L. Eden, "From the editors: Common method variance in international business research," Journal of International Business Studies, vol. 41, no. 2, pp. 178-184, 2010.

\section{Authors' Profiles}

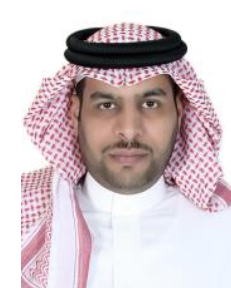

Mutlaq B. Alotaibi is an Associate Professor of Information Systems at $\mathrm{Al}$ Imam Mohammad Ibn Saud Islamic University (IMSIU). In 2010, he was appointed Head of the IS Department. In 2012, he was appointed as the Vice Dean for Academic Affairs at the College of Computer and Information Sciences. His main research interests are in the area of interactive systems, particularly in multimodal interaction and adaptive user interfaces. He is also interested in IS research, particularly consumer behaviour, and in the application of user acceptance of technologies. He has publications in the fields of, e-business and e-commerce, customer knowledge management, customer relationship management, cloud computing, mobile computing and usability heuristics.

How to cite this paper: Mutlaq B. Alotaibi,"Modelling Electronic Sharing (E-Sharing) Behaviour: A Perspective on Location-aware Technology", International Journal of Intelligent Systems and Applications(IJISA), Vol.9, No.1, pp.20-29, 2017. DOI: 10.5815/ijisa.2017.01.02 